thrombolysis. The company has been active in helping to encourage the adoption of fast track systems to ensure that patients are treated as early as possible. Taking thrombolysis out of the hospital and into the community without adequate cardiological support may not, however, be the best way of ensuring that patients receive the earliest and most appropriate treatment.

ANTHONY K HALL Medical adviser D M HUMPHREYS Medical director

Boehringer Ingelheim

Bracknell, Berkshire RG12 8YS

1 Rawles J. Treatment of myocardial infarction and angina. $B M F$ 1995;310:465. (18 February.)

2 McMurray J, Rankin A. Cardiology. I. Treatment of myocardial infarction, unstable angina, and angina pectoris. BMF 1994, 309:1343-50. (19 November.)

3 Fibrinolytic Therapy Trialists' Collaborative Group. Indications for fibrinolytic therapy in suspected acute myocardial infarction: collaborative overview of early mortality and major morbidity results from all randomised trials of more than 1000 patients. Lancet 1994;343:311-22.

4 GUSTO Angiographic Investigators. The effect of tissue plasminogen activator, streptokinase, or both on coronaryartery patency, ventricular function, and survival after acute myocardial infarction. N Engl f Med 1993;329:1615-22.

\section{Carotid endarterectomy}

\section{Author's reply}

EDITOR,-Many of those who commented in the debate on carotid endarterectomy suggested that the use of non-invasive tests for carotid stenosis can transform the balance of risks and benefits to patients of a service for carotid endarterectomy. ${ }^{12}$ This may overstate the case.

These tests should firstly be exposed to a more comprehensive formal evaluation; it should not stop at small case series assessing only accuracy, as this represents an inadequate assessment of these technologies. The acceptability, reproducibility, and economics of these investigative techniques requires more examination.

We should not be surprised that some centres with considerable expertise are able to achieve high levels of accuracy, but this may be unrepresentative of what happens in many centres carrying out investigation and surgery. This process of evaluation should therefore extend to a local level, with each service carrying out an audit of the investigation pathways used locally, and should examine the accuracy of these tests when the investigators are blinded to the results of any previous investigations.

Even if we were to ensure that this process of evaluation and audit did happen, the benefits for the individual and for the population are likely to be marginal. For example, increasing the sensitivity of carotid Doppler ultrasonography from perhaps $80 \%$ to $95 \%$ to attain a positive predictive value of $90 \%$, and discontinuing conventional angiography, might increase the number of strokes saved in England from 116 to 146 (using the sample collected by Hankey and Warlow ${ }^{3}$ ), but only if we assume that the operation has no net effect on the 208 people who would have had an unnecessary operation. If we then introduce a second noninvasive test (perhaps magnetic resonance angiography), optimised to achieve, perhaps, a sensitivity of $95 \%$, this might save as many strokes (146), but only if we assume that it identifies all those incorrectly assigned as having severe carotid stenosis by the first test (hence no one will be exposed to the risk of unnecessary surgery). The most optimistic assessment of the effect of a carotid endarterectomy service in England then rises from $0 \cdot 14 \%$ to $0 \cdot 15 \%$ of strokes saved. If we are to have such a service, improving investigation pathways may well be important for individual patients, but commissioners will still need to think carefully about whether even a technologically updated

(and perhaps more costly) service is worth their investment.

MARK LAMBERT Senior registrar in public health medicine Nuffield Institute for Health, Leeds L52 9PL

1 Baird RN, Lambert M. Should carotid endarterectomy be purchased? BMF 1995:310:316-8. (4 February.)

Correspondence. Carotid endarterectomy. BMf 1995;310:11356. (29 April.)

3 Hankey JH, Warlow CP. Symptomatic carotid ischaemic events: safest and most cost effective way of selecting patients for angiography before carotid endarterectomy. BMf 1990;300: 1485-91.

\section{Influence of patient's age on GPs' definition of hypertension}

\section{Patients aged over 80 may not benefit from antihypertensive treatment}

EDIToR,-J E C Dickerson and M J Brown explore the influence of patients' ages on general practitioners' reported management of hypertension but include all patients aged $\geqslant 65$ in one category. ${ }^{1}$ While it has been shown that treatment of hypertension is beneficial in people aged $65-80$, there is no good evidence that it is warranted in those aged over $80 .^{2}$ Asking what are the lowest blood pressures at which general practitioners would both define and treat hypertension in this heterogeneous age group is therefore ambiguous, and the responses are difficult to interpret.

If, however, we accept the data at their face value it is useful to look for reasons why general practitioners' reported practices are at variance with the recommended guidelines. The increase in the threshold blood pressure at which general practitioners report starting treatment with age could be explained by the fact that general practitioners care for all over 65 year olds, while healthier subgroups have been studied in trials. In the Medical Research Council's trial, for instance, the participants were fit enough to attend for screening (68\% responded to an invitation). ${ }^{3}$ Even in this ambulant group 565 patients with hypertension ( $11 \%$ of those identified) were excluded from randomisation because of pre-existing disease and 575 patients (13\%) were withdrawn from their allocated treatment groups because of side effects. Patients not enrolled into trials of antihypertensive drugs will therefore be more likely to suffer from other health problems and may be less likely to tolerate antihypertensive agents.

General practitioners' experiences in caring for this portion of the elderly, hypertensive population may have contributed towards their reported management of hypertension. This may explain why general practitioners seem reluctant to consider starting antihypertensive drugs in the over $65 \mathrm{~s}$, reserving this intervention for patients with the highest blood pressures and the greatest chances of morbidity.

Faculty of Medicine,

University of Leicester,

Leicester General Hospital,

Leicester LE5 4PW

1 Dickerson JEC, Brown MJ. Influence of age on general practitioners' definition and treatment of hypertension. $B M F$ 1995; 310:574. (4 March.)

2 Sever B, Beevers G, Bulpitt C, Lever A, Ramsay L, Reid J, et al. Management guidelines in essential hypertension: report of the second working party of the British Hypertensive Society. BMF 1993;306:983-7.

3 MRC Working Party. Medical Research Council trial of treatment in older adults: principal results. $B M^{\mathcal{F}} 1992 ; 304: 405-12$.

\section{General practitioners' age may influence management of hypertension}

EDrTor,-The paper on the influence of patients' ages on general practitioners' definitions and treatment of hypertension does not mention the ages of the general practitioners. ${ }^{1}$ Last year we asked all of the general practitioners in Avon $(n=542)$ to state the minimum blood pressure that would make them consider starting drug treatment for a man aged 40 with no cardiovascular risk factors; 325 $(60 \%)$ responded. We also asked the general practitioners whether they would start drug treatment for a 70 year old woman, also with no additional cardiovascular risk factors, with a consistent blood pressure of $180 / 100 \mathrm{~mm} \mathrm{Hg}$. Overall, we found that 269 general practitioners would start drug treatment at or below $160 / 100 \mathrm{~mm} \mathrm{Hg}$, and 244 $(75 \%)$ would start drug treatment for the woman. However, we found a significant linear association when we examined the general practitioners by age group (table).

Proportions of general practitioners according to age who would start drug treatment for hypertension at various blood pressures

\begin{tabular}{|c|c|c|c|c|}
\hline \multirow[b]{2}{*}{$\begin{array}{l}\text { Blood } \\
\text { pressure } \\
\text { (mm Hg) }\end{array}$} & \multicolumn{4}{|c|}{ Age of general practitioner (years) } \\
\hline & $\begin{array}{cc}<36 & 36-45 \\
(n=75) & (n=143)\end{array}$ & $\begin{array}{c}46-55 \\
(n=84)\end{array}$ & $\begin{array}{c}>55 \\
(n=23)\end{array}$ & $\begin{array}{c}\text { Comparison } \\
\text { between } \\
\text { age groups }\end{array}$ \\
\hline \multicolumn{5}{|c|}{ For 40 year old man with no other risk factors } \\
\hline $140 / 90$ & $1(1) \quad 5(3)$ & $4(5)$ & $3(13)$ & NS ${ }^{\star}$ \\
\hline 150/95 & $20(14)$ & $19(23)$ & $8(35)$ & $P<0.05$ \\
\hline $160 / 100$ & $56(75) 122(85)$ & $74(88)$ & $17(74)$ & NS \\
\hline $170 / 105$ & 69 (92) $134(94)$ & $82(98)$ & $22(96)$ & NS \\
\hline \multicolumn{5}{|c|}{ For 40 year old man who smokes } \\
\hline $140 / 90$ & $3(4) \quad 6(4)$ & $9(11)$ & $4(17)$ & $P<0.05$ \\
\hline 150/95 & $10(13) 30(21)$ & $29(35)$ & $11(48)$ & $P<0.001$ \\
\hline $160 / 100$ & $62(83) 126(88)$ & $78(93)$ & $18(78)$ & NS \\
\hline 170/105 & $72(96) 137(96)$ & $83(99)$ & $22(96)$ & NS \\
\hline \multicolumn{5}{|c|}{ For 70 year old woman with no other risk factors } \\
\hline $180 / 100$ & $62(83) 109(76)$ & $60(71)$ & $13(57)$ & NS* \\
\hline
\end{tabular}

${ }^{\star}$ Mantel-Haenszel test for linear association $\mathrm{P}<0.05$.

We were intrigued to find this tendency and wonder why older general practitioners seem to be keener to treat younger people and not start treatment in elderly people. If a risk factor (cigarette smoking) is introduced into the scenario of the 40 year old patient the thresholds for treatment change but the effect of age remains.

We also asked the local consultant physicians, who commonly manage patients with hypertension, at what blood pressure they would expect a general practitioner to start drug treatment. Although a higher percentage $(87 \%)$ would treat the $\mathbf{7 0}$ year old woman, they expected the general practitioners to start treatment at considerably lower blood pressures than described above, and well below the British Hypertension Society's guidelines.

It is difficult to see how patients will obtain consistent advice about the management of blood pressure with these widely differing opinions.

MICHAEL WHTTFIELD Consultant senior lecturer in general practice ANTHONY HUGHES Senior lecturer in statistics

Department of Social Medicine,

University of Bristol,

Bristol BS8 2PR

1 Dickerson JEC, Brown MJ. Influence of age on general practitioners' definition and treatment of hypertension. $B M \mathcal{F} 1995$ tioners' definition and

\section{The World Health Organisation}

\section{Changes require consistent action and long term vision by the WHO}

EDITOR,-Of Fiona Godlee's articles on the World Health Organisation, the one on the European office is of particular concern to me. ${ }^{1}$ Two of the concluding sentences in this article accurately summarise the work of this office: "Through the Health for All initiative, WHO's European office has had a profound influence on the debate on health in Europe. The office has also shown itself 